\title{
A prospective study of stroke sub-type from within an incident population in Tanzania
}

\author{
Richard W Walker, Ahmed Jusabani, Eric Aris, William K Gray, Dipayan Mitra, Mark Swai
}

Objectives. We aimed to establish the pathological types of stroke in two incident populations in Tanzania, one rural and one urban, and to examine the clinical utility of the Siriraj and Allen scores in identifying stroke sub-types.

Design. This prospective community-based study identified cases as part of a stroke incidence study. Each patient underwent a full assessment including recording demographic information, taking a medical and drug history, and physical examination. A computed tomography (CT) head scan was used to classify strokes as resulting from a cerebral haemorrhage or ischaemia. The results were compared with the Siriraj and Allen scores, obtained from clinical findings.

Results. One hundred and thirty-two incident stroke cases were identified in the rural Hai demographic surveillance site (DSS) and
69 in the urban Dar-es-Salaam DSS; 63 patients with stroke due to ischaemia or cerebral haemorrhage from Hai and 17 from Dares-Salaam had a CT scan within 15 days of the stroke. Stroke was identified as due to ischaemia in 52 cases $(82.5 \%)$ and to cerebral haemorrhage in $11(17.5 \%)$ in Hai, and as due to ischaemia in 14 cases $(82.4 \%)$ and to cerebral haemorrhage in $3(17.6 \%)$ in Dar-esSalaam. In both sites Siriraj and Allen scores were found to be of little value in predicting stroke sub-type.

Conclusions. The ratio of ischaemic to haemorrhagic stroke is much higher in our cohort than previously reported in sub-Saharan Africa, and is closer to that in high-income countries.

S Afr Med J 2011;101:338-344
Stroke is an increasingly important cause of premature death and chronic disability in many low- and middle-income countries. ${ }^{1}$ Worldwide, strokes resulting from ischaemia are much more common than those due to cerebral haemorrhage. A study of 3000 hospitalised first-in-a-lifetime stroke patients across 22 countries found that overall $22 \%$ of strokes were due to cerebral haemorrhage and $78 \%$ to ischaemia. ${ }^{2}$ The percentage due to cerebral haemorrhage was lowest in high-income countries, where $9 \%$ were due to cerebral haemorrhage and $91 \%$ to ischaemia. Sites in Africa (Mozambique, Nigeria, South Africa, Sudan and Uganda) had the highest percentage of strokes due to cerebral haemorrhage, at $34 \%$.

In Europe and North America, studies have suggested rates of 10 $20 \%$ for stroke due to cerebral haemorrhage..$^{3-5}$ Data on stroke subtype in sub-Saharan Africa (SSA) are much less reliable, with rates of 29 - 57\% reported for cerebral haemorrhage. ${ }^{6-9}$ This variability in the incidence of stroke sub-types, both within SSA and between SSA and high-income countries, may partly be due to the low numbers in

North Tyneside General Hospital, Rake Lane, North Shields, Tyne and Wear, and Institute of Health and Society, University of Newcastle-upon-Tyne, UK Richard W Walker, MD

Kilimanjaro Christian Medical Centre, Moshi, United Republic of Tanzania Ahmed Jusabani, MD

Mark Swai, MD

Department of Neurology, Muhimbili University Hospital, Dar-es-Salaam, United Republic of Tanzania

Eric Aris, MD

North Tyneside General Hospital

William K Gray, PhD

Department of Neuroradiology, Newcastle General Hospital, Newcastle-upon-Tyne Dipayan Mitra, MB BS

Correspondence to: $R$ Walker (Richard.walker@nhct.nhs.uk) these studies, lack of access to computed tomography (CT) scanning equipment, and the fact that all were hospital-based. In SSA, because of limited resources, often only patients with more severe symptoms are admitted to hospital. Such patients are likely to have had a stroke due to cerebral haemorrhage rather than an ischaemic stroke. In SSA neuro-imaging devices are often not available or too expensive for routine use, and the diagnosis of stroke sub-type is usually made clinically. ${ }^{10}$ Nevertheless, clinicians must know the type of stroke that has occurred to avoid administration of anticoagulant, antiplatelet or thrombolytic agents to patients who have had a cerebral haemorrhage.

Studies have investigated the utility of clinical diagnostic tools, such as the Allen (or Guy's hospital) score ${ }^{11}$ and the Siriraj score, ${ }^{12}$ in high-income countries, ${ }^{13-16}$ but there have been few from SSA. ${ }^{6-9}$ Of 222 strokes in consecutive black patients admitted to a Johannesburg hospital, $152(68.5 \%)$ were due to cerebral haemorrhage and 70 $(31.5 \%)$ ischaemic, and both the Allen and Siriraj scores were found to be poor at differentiating intracerebral haemorrhage from ischaemia as the cause. ${ }^{6}$

Our primary aim was to establish the incidence of stroke sub-type in an incident population in Tanzania, East Africa. ${ }^{17}$ Secondary aims were to establish the utility of the Siriraj and Allen scoring systems in the diagnosis of stroke sub-type and to examine individual clinical examination findings as predictors of stroke sub-type.

\section{Patients and methods}

Ethical approval was obtained from the National Institute of Medical Research, Tanzania, and the Newcastle and Northumberland Joint Ethics Committee, UK.

\section{Recruitment}

The Tanzanian Stroke Incidence Project (TSIP) prospectively recruited patients from 15 June 2003 until 15 June 2006 at two demographic surveillance sites (DSS) in Tanzania: rural Hai and urban Dar-es-Salaam. ${ }^{17}$ Both sites have been described previously as part of the Adult Morbidity and Mortality Project (AMMP). ${ }^{18}$ The TSIP was extensively advertised within the study areas and paid for participants to attend hospital and receive treatment for the first year 
after their stroke. A system of verbal autopsy (VA) was also used to identify stroke cases that were only identified after death. During the 3 -year study 453 incident strokes (132 by TSIP and 346 by VA, with 25 overlapping cases) were identified in Hai and 183 in Dar-esSalaam ( 69 by TSIP and 114 by VA, with no overlapping cases).

\section{Measurement}

Demographic information, social history, past medical history and information about events around the time of the stroke were recorded as part of the TSIP. All participants underwent medical assessment and examination including recording blood pressure no less than 7 days after the stroke, pulse rate, cardiac auscultatory findings, height and weight, physical function (Barthel index ${ }^{19}$ modified Rankin scale $^{20}$ ), neurological status (communication, swallowing, vision, muscle activity, sensation), an echocardiogram, a chest radiograph and a CT brain scan. Hypertension was defined as a blood pressure higher than $160 \mathrm{mmHg}$ systolic or $90 \mathrm{mmHg}$ diastolic no less than 7 days after the stroke. CT scans were analysed independently by a general radiologist at Kilimanjaro Christian Medical Centre, Tanzania (AJ) and a neuro-radiologist from Newcastle General Hospital, UK (DM), and the diagnoses of ischaemic stroke and cerebral haemorrhage were compared. In the event of a difference of opinion with regard to diagnosis, a consensus was reached. An intracerebral bleed was classified as stroke due to cerebral haemorrhage. Findings of ischaemia, haemorrhagic infarct, or no evidence of stroke were classified as ischaemic stroke. No evidence of stroke on the CT scan was taken as evidence of ischaemic stroke, since CT would indicate cerebral or subarachnoid haemorrhage less than 15 days after a stroke. More than 15 days after a stroke, some cases of stroke due to small haemorrhage may not be apparent on the CT scan, leading to possible misclassification. Cases diagnosed as subarachnoid haemorrhage by CT scan were excluded. The Siriraj score $^{12}$ and Allen score ${ }^{11}$ were calculated based on clinical findings, as originally described.

\section{Statistics}

The data were quantitative and collected at a nominal, ordinal and interval/ratio level. Data were analysed using standard statistical software, PASW-18 for Windows (SPSS, Chicago, IL, USA). All variables were found to be non-normally distributed (KolmogorovSmirnov test) and so did not meet parametric assumptions. The Mann-Whitney U-test and Pearson's chi-square test (categorical data) were therefore used to characterise differences between groups. Correlation between variables was established by point biserial test.

\section{Results \\ Hai district}

One hundred and thirty-two incident stroke cases were identified in the Hai DSS between 15 June 2003 and 15 June 2006 as part of the TSIP study. One case of subarachnoid haemorrhage was excluded from further analysis. The median time from incident stroke to assessment interview was 10 days (range 0 - 252 days). Although every attempt was made to assess and examine stroke cases as soon after incident stroke as possible, 22 died shortly before being identified and 2 died before a full examination could take place. In addition, 44 cases did not have a CT scan until 15 days or more after the stroke owing to a delay in identification as a stroke case or in attendance at hospital after identification. Therefore, 63 cases had a CT head scan within 15 days of incident stroke. The mean age of the 63 cases was 67.4 years (range 23 - 94, standard deviation (SD) 14.0) and $34(54.0 \%)$ were male. Age and gender of those who had a CT scan within 15 days are compared with those who did not in Table
I. Fifty-two (82.5\%) had had an ischaemic stroke and $11(17.5 \%)$ a stroke due to cerebral haemorrhage.

Of patients who had a CT scan within 15 days, 5 with ischaemic stroke had had one previous stroke and 2 with ischaemic stroke had had two previous strokes. No patient with a haemorrhagic stroke had had a previous stroke. Stroke sub-type was not significantly associated (chi-square test or point-biserial correlation) with age, sex, 3 - 6-year mortality, findings on the electrocardiogram or echocardiogram, smoking history, alcohol consumption or a pre-stroke diagnosis of angina, diabetes or hypertension.

\section{Dar-es-Salaam district}

Sixty-nine stroke cases were identified in the Dar-es-Salaam DSS between 15 June 2003 and 15 June 2006 as part of the TSIP study. The median time from incident stroke to assessment interview was 37 days (range 0 - 491 days). Although every attempt was made to assess and examine stroke cases as soon after incident stroke as possible, 7 died shortly before being identified. In addition, 45 cases did not have a CT scan until 15 days or more after the stroke owing to a delay in identification as a stroke case or in attendance at hospital after identification. Of the 17 cases who had a CT scan within 15 days of incident stroke, $14(82.4 \%)$ had had an ischaemic stroke and $3(17.6 \%)$ a cerebral haemorrhage. For 1 case age could not be reliably obtained. The mean age of the remaining 16 cases was 57.7 years (range 30 - 84, SD 15.4) and 8 (47.1\%) were male. Age and gender of those who had a CT scan within 15 days are compared with those who did not in Table I.

Of those who had had a CT scan within 15 days, 1 patient with haemorrhagic stroke had had a previous stroke. There were no significant differences in age, gender, Barthel index or blood pressure readings between the two groups. Given the limited number of cases, it was not possible to find meaningful associations of stroke sub-type with clinical findings.

The odds of having a stroke due to cerebral haemorrhage (rather than due to ischaemia) in Hai compared with Dar-es-Salaam were 1.01 (95\% confidence interval (CI) $0.49-2.09$ ).

\section{Siriraj and Allen scores}

A Siriraj score and an Allen score could be calculated for 60 of the 63 patients from Hai and 16 of the 17 from Dar-es-Salaam who had a CT scan within 15 days of incident stroke. The remaining 4 patients did not have sufficient information recorded. The comparisons between Siriraj and Allen scores and CT scan results are shown in Table II for Hai and in Table III for Dar-es-Salaam.

For Hai patients, using an alternative cut-off of Siriraj score $<1$ for ischaemic stroke and $\geq 1$ for cerebral haemorrhage, an accuracy of $70.0 \%$ was achieved; using a cut-off of Allen score $\leq 27$ for ischaemic stroke and $>27$ for cerebral haemorrhage, an accuracy of $74.6 \%$ was achieved (Table IV). For Dar-es-Salaam patients using an alternative cut-off of Siriraj score $\leq 1$ for ischaemic stroke and $>1$ for cerebral haemorrhage and a cut-off of Allen score $\leq 20$ for ischaemic stroke and $>20$ for cerebral haemorrhage, an accuracy of $81.2 \%$ was achieved in both cases (Table V).

\section{Hypertension}

\section{Hai district}

Using a cut off of $>160 \mathrm{mmHg}$ systolic or $90 \mathrm{mmHg}$ diastolic for hypertension, 50 (48.1\%) of 104 participants who had their blood pressure recorded at interview had hypertension. Of these 50, $31(62.0 \%)$ reported a history of hypertension, $21(42.0 \%)$ were currently taking antihypertensives, $24(48.0 \%)$ had been taking antihypertensives before their stroke, 30 (60.0\%) had had their blood 


\section{Original ArTiCles}

Table I. Demographic information for patients with CT scan within 15 days and those without CT scan or CT scan done after 15 days

\begin{tabular}{|c|c|c|c|c|c|}
\hline & & & $\begin{array}{l}\text { CT scan carried out } \\
\text { within } 15 \text { days }\end{array}$ & $\begin{array}{l}\text { CT scan not carried } \\
\text { out within } 15 \text { days }\end{array}$ & $\begin{array}{l}\text { Significance of } \\
\text { difference }\end{array}$ \\
\hline \multirow[t]{18}{*}{ Hai } & $N$ & & 63 & 68 & \\
\hline & \multirow[t]{4}{*}{ Age } & Mean & 67.4 & 70.0 & $\begin{array}{l}U=1836.0, z=-1.411, \\
p=0.158\end{array}$ \\
\hline & & Range & $23-94$ & $29-100$ & \\
\hline & & $\mathrm{SD}$ & 14.065 & 15.515 & \\
\hline & & $95 \% \mathrm{CI}$ & $63.90-71.00$ & $66.24-73.76$ & \\
\hline & \multirow[t]{4}{*}{ Barthel index } & Mean & 7.64 & 10.26 & $\begin{array}{l}U=965.0, z=-1.896, \\
p=0.058\end{array}$ \\
\hline & & Range & $0-20$ & $0-20$ & \\
\hline & & $\mathrm{SD}$ & 7.644 & 6.886 & \\
\hline & & $95 \% \mathrm{CI}$ & $5.80-9.49$ & $8.12-12.41$ & \\
\hline & \multirow[t]{4}{*}{$\begin{array}{l}\text { Diastolic blood } \\
\text { pressure }\end{array}$} & Mean & 98.1 & 91.2 & $\begin{array}{l}U=1159.5, z=-1.064, \\
p=0.288\end{array}$ \\
\hline & & Range & $60.0-181.0$ & $50.0-134.0$ & \\
\hline & & $\mathrm{SD}$ & 26.247 & 19.326 & \\
\hline & & $95 \% \mathrm{CI}$ & $991.35-104.91$ & $85.35-97.10$ & \\
\hline & \multirow[t]{4}{*}{$\begin{array}{l}\text { Systolic blood } \\
\text { pressure }\end{array}$} & Mean & 154.9 & 151.7 & $\begin{array}{l}U=1212.0, z=-0.712, \\
p=0.476\end{array}$ \\
\hline & & Range & $60.0-260.0$ & $80.0-284.0$ & \\
\hline & & $\mathrm{SD}$ & 37.719 & 35.548 & \\
\hline & & $95 \% \mathrm{CI}$ & $145.12-164.61$ & $140.92-162.54$ & \\
\hline & Gender & $\operatorname{Males}(N(\%))$ & $34(54.0)$ & $35(51.5)$ & $\chi^{2}(1)=0.082, p=0.861$ \\
\hline \multirow[t]{18}{*}{ Dar-es-Salaam } & $N$ & & 17 & 52 & \\
\hline & \multirow[t]{4}{*}{ Age } & Mean & 57.8 & 62.4 & $\begin{array}{l}U=342.500, z=-1.064, \\
p=0.292\end{array}$ \\
\hline & & Range & $30-84$ & $29-82$ & \\
\hline & & $\mathrm{SD}$ & 15.356 & 13.499 & \\
\hline & & $95 \% \mathrm{CI}$ & $50.02-65.47$ & $58.64-66.02$ & \\
\hline & \multirow[t]{4}{*}{ Barthel index } & Mean & 19.88 & 19.53 & $\begin{array}{l}U=359.500, z=-0.189, \\
p=1.000\end{array}$ \\
\hline & & Range & $19-20$ & $6-20$ & \\
\hline & & SD & 0.332 & 2.186 & \\
\hline & & $95 \% \mathrm{CI}$ & $19.72-20.04$ & $18.88-20.18$ & \\
\hline & \multirow[t]{4}{*}{$\begin{array}{l}\text { Diastolic blood } \\
\text { pressure }\end{array}$} & Mean & 90.12 & 97.03 & $\begin{array}{l}U=282.500 \quad z=-1.271, \\
p=0.207\end{array}$ \\
\hline & & Range & $63.5-122.5$ & $60.0-133.5$ & \\
\hline & & SD & 18.881 & 18.007 & \\
\hline & & $95 \% \mathrm{CI}$ & $80.88-99.37$ & $91.77-102.29$ & \\
\hline & \multirow[t]{4}{*}{$\begin{array}{l}\text { Systolic blood } \\
\text { pressure }\end{array}$} & Mean & 149.25 & 158.66 & $\begin{array}{l}U=310.500, z=-0.812, \\
p=0.423\end{array}$ \\
\hline & & Range & $84.0-216.0$ & $101.0-234.0$ & \\
\hline & & $\mathrm{SD}$ & 36.960 & 35.110 & \\
\hline & & $95 \% \mathrm{CI}$ & $131.14-167.36$ & $148.40-168.92$ & \\
\hline & Gender & Males $(N(\%))$ & $8(47.1)$ & $30(57.7)$ & $\chi^{2}(1)=0.585, p=0.576$ \\
\hline
\end{tabular}

pressure monitored in the past 12 months, and $15(30.0 \%)$ had never had their blood pressure measured. Having hypertension was not significantly associated with stroke sub-type $\left(\chi^{2}(1)=0.842, p=0.559\right)$, with 6 of the 11 who had a cerebral haemorrhage and 24 of the 49 
Table II. CT scan results compared with Siriraj and Allen scores for Hai patients

\begin{tabular}{|c|c|c|c|c|}
\hline & & \multicolumn{2}{|c|}{ CT scan result } & \multirow[b]{2}{*}{ Total } \\
\hline & & Haemorrhage & Ischaemia & \\
\hline \multirow[t]{11}{*}{ Siriraj score } & Stroke due to cerebral haemorrhage & 7 & 15 & 22 \\
\hline & Ischaemic stroke & 3 & 21 & 24 \\
\hline & Indeterminate & 1 & 13 & 14 \\
\hline & Total & 11 & 49 & 60 \\
\hline & $\kappa^{*} \dagger$ & 0.238 & 0.107 & \\
\hline & Sensitivity ${ }^{*}$ & 0.636 & 0.429 & \\
\hline & Specificity ${ }^{*}$ & 0.694 & 0.727 & \\
\hline & Positive predictive value ${ }^{\star}$ & 0.318 & 0.875 & \\
\hline & Likelihood ratio for a positive score ${ }^{*}$ & 2.078 & 1.571 & \\
\hline & Likelihood ratio for a negative score & 0.524 & 0.785 & \\
\hline & \multicolumn{3}{|c|}{ indeterminate scores removed) } & \\
\hline \multirow[t]{11}{*}{ Allen score } & Stroke due to cerebral haemorrhage & 7 & 18 & 25 \\
\hline & Ischaemic stroke & 1 & 17 & 18 \\
\hline & Indeterminate & 3 & 14 & 17 \\
\hline & Total & 11 & 49 & 60 \\
\hline & $\kappa^{*} \dagger$ & 0.180 & 0.205 & \\
\hline & Sensitivity ${ }^{*}$ & 0.636 & 0.347 & \\
\hline & Specificity* & 0.633 & 0.909 & \\
\hline & Positive predictive value ${ }^{*}$ & 0.280 & 0.944 & \\
\hline & Likelihood ratio for a positive score ${ }^{*}$ & 1.733 & 3.813 & \\
\hline & Likelihood ratio for a negative score & 0.575 & 0.718 & \\
\hline & \multicolumn{3}{|c|}{$\begin{array}{l}0.400 \text { ( } 0.558 \text { with } \\
\text { indeterminate scores removed) }\end{array}$} & \\
\hline \multicolumn{5}{|c|}{$\begin{array}{l}\text { "Value refers to statistic for cases with stroke sub-type (haemorrhage or ischaemia) v. all other cases, as such indeterminate cases are included. } \\
{ }^{\top} \text { Values indicate the level of agreement between the score and the CT scan result: } 0.0 \text { - } 0.2 \text { slight agreement; } 0.2-0.4 \text { fair agreement; } 0.4-0.6 \text { moderate agreement; } 0.6-0.8 \text { good/substantial } \\
\text { agreement; } 0.8-1.0 \text { almost perfect agreement. }{ }^{33}\end{array}$} \\
\hline
\end{tabular}

who had an ischaemic stroke (and had blood pressure measured) having hypertension. Using a lower cut-off of $\geq 140 / 90 \mathrm{mmHg}$, used by some authors, 77 participants $(73.3 \%)$ were hypertensive. ${ }^{5}$

\section{Dar-es-Salaam district}

Using the $160 / 90 \mathrm{mmHg}$ cut-off, of 61 participants who had their blood pressure recorded at interview, 37 (60.7\%) had hypertension. Of these, $21(56.8 \%)$ reported a history of hypertension, $14(37.8 \%)$ were currently taking antihypertensives, $7(18.9 \%)$ had been taking hypertensives before their stroke, 11 (29.7\%) had had their blood pressure monitored in the past 12 months, and 17 (45.5\%) had never had their blood pressure measured. Using the lower cutoff $(140 / 90 \mathrm{mmHg}), 45$ participants $(73.8 \%)$ were hypertensive. Having hypertension was not significantly associated with stroke sub-type $\left(\chi^{2}(1)=0.788, p=0.550\right)$, with 2 of the 3 who had a cerebral haemorrhage and 5 of the 13 who had an ischaemic stroke (and had blood pressure measured) having hypertension. Hypertension was not significantly associated with stroke sub-type. Using the lower cutoff (140/90 $\mathrm{mmHg}), 45$ (73.8\%) participants were hypertensive.

The odds of having hypertension in Dar-es-Salaam compared with Hai were 1.67 (95\% CI 0.95 - 2.92).

\section{Discussion}

Our prospective study of incident stroke cases occurring in a rural and an urban area of Tanzania, East Africa, reveals a lower incidence of stroke due to cerebral haemorrhage compared with ischaemic stroke than in previous studies in SSA., ${ }^{2,-9}$ Considering only those patients seen within 15 days after their stroke, the percentage of haemorrhagic and ischaemic strokes was similar in both areas. The percentage of strokes due to cerebral haemorrhage and the mean age of participants were similar to studies in high-income countries. ${ }^{2,5,14,21}$ Participants were much older than in previous studies from SSA., ${ }^{2,5,6,9}$ In a resource-poor setting younger people may be more likely to be taken to hospital.

The lack of data on cases picked up by the VA system (i.e. patients who died soon after their stroke), and including only those cases identified by TSIP who were able to have a CT scan within 15 days of stroke, mean that our data may have a bias. We cannot discount the possibility that patients who died rapidly following stroke, or were unable to have a CT scan for other reasons, may have been more likely to have had a cerebral haemorrhage. Our percentage of strokes due to haemorrhage was around half of that for SSA reported in the INTERSTROKE study, in which stroke patients were recruited from hospital admissions only if they had had a CT scan. ${ }^{2}$ Whether this 
Table III. CT scan results compared with Siriraj and Allen scores for Dar-es-Salaam patients

\begin{tabular}{|c|c|c|c|c|}
\hline & & \multicolumn{2}{|c|}{ CT scan result } & \multirow[b]{2}{*}{ Total } \\
\hline & & Haemorrhage & Ischaemia & \\
\hline \multirow[t]{11}{*}{ Siriraj score } & Stroke due to cerebral haemorrhage & 2 & 2 & 4 \\
\hline & Ischaemic stroke & 0 & 7 & 7 \\
\hline & Indeterminate & 1 & 4 & 5 \\
\hline & Total & 3 & 13 & 16 \\
\hline & $\kappa^{*} \dagger$ & 0.455 & 0.304 & \\
\hline & Sensitivity ${ }^{*}$ & 0.667 & 0.538 & \\
\hline & Specificity $^{*}$ & 0.846 & 1.000 & \\
\hline & Positive predictive value ${ }^{*}$ & 0.500 & 1.000 & \\
\hline & Likelihood ratio for a positive score ${ }^{*}$ & 4.331 & - & \\
\hline & Likelihood ratio for a negative score & 0.394 & 0.462 & \\
\hline & Accuracy & $\begin{array}{c}0.562 \text { ( } 0.818 \text { with } \\
\text { indeterminate scores } \\
\text { removed) }\end{array}$ & & \\
\hline \multirow[t]{11}{*}{ Allen score } & Stroke due to cerebral haemorrhage & 1 & 1 & 2 \\
\hline & Ischaemic stroke & 1 & 8 & 9 \\
\hline & Indeterminate & 1 & 4 & 5 \\
\hline & Total & 3 & 13 & 16 \\
\hline & $\kappa^{*} \dagger$ & 0.294 & 0.186 & \\
\hline & Sensitivity ${ }^{*}$ & 0.333 & 0.615 & \\
\hline & Specificity* & 0.923 & 0.666 & \\
\hline & Positive predictive value ${ }^{*}$ & 0.500 & 0.888 & \\
\hline & Likelihood ratio for a positive score ${ }^{*}$ & 4.325 & 1.848 & \\
\hline & Likelihood ratio for a negative score ${ }^{*}$ & 0.721 & 0.577 & \\
\hline & Accuracy & $\begin{array}{c}0.562 \text { ( } 0.818 \text { with } \\
\text { indeterminate scores } \\
\text { removed) }\end{array}$ & & \\
\hline \multicolumn{5}{|c|}{$\begin{array}{l}\text { †Values indicate the level of agreement between the score and the CT scan result: } 0.0-0.2 \text { slight agreement; } 0.2-0.4 \text { fair agreement; } 0.4-0.6 \text { moderate agreement; } 0.6-0.8 \text { good/substantial } \\
\text { agreement; } 0.8 \text { - } 1.0 \text { almost perfect agreement. }{ }^{33}\end{array}$} \\
\hline
\end{tabular}

difference reflects regional differences in stroke risk factors, an underestimate of stroke due to cerebral haemorrhage in our study (due to early death of those having had a haemorrhage), or an over-estimate of stroke due to cerebral haemorrhage in the INTERSTROKE study (due to those with haemorrhage being more likely to be hospitalised), is not clear. However, reports of stroke sub-type incidence from hospital-based studies are likely to be unrepresentative of the entire population of those having strokes. In a UK-based study the odds of being admitted to hospital having had a primary intracerebral haemorrhage were 2.54 those of being admitted having had an ischaemic stroke. ${ }^{22-23}$ Furthermore, we have previously reported that in Tanzania only $56 \%$ of stroke deaths occur in hospitals, suggesting that it may not be possible to draw firm conclusions regarding the relative proportions of stroke sub-types from hospital-based studies. ${ }^{24}$ We therefore suggest this study is likely to represent the most accurate estimate of stroke sub-type incidence in SSA to date.

Previous studies comparing white and black stroke populations have found a higher incidence of stroke due to cerebral haemorrhage in black populations with a higher incidence of risk factors for cerebral haemorrhage, specifically hypertension., ${ }^{25,25-26}$ In our study, although hypertension was found in $48.1 \%$ of cases in Hai and $60.7 \%$ in Dares-Salaam, it was not significantly associated with a higher incidence of cerebral haemorrhage. Studies of the general population have indicated an age-standardised rate of hypertension in the Hai DSS of $13.1 \%$ in men and $13.3 \%$ in women, and in the Dar-es-Salaam DSS of $18.5 \%$ in men and $22.0 \%$ in women using a cut off of $>160 / 90 \mathrm{mmHg}$, indicating higher levels of hypertension in those who have had a stroke than in the general population. ${ }^{27}$ Other risk factors for stroke such as smoking, alcohol consumption, diabetes, angina and cardiac function (auscultation, ECG and echocardiogram) were not significantly associated with stroke sub-type. Swai et al. ${ }^{28}$ noted a lower prevalence of risk factors for coronary heart disease and ischaemic stroke (smoking, alcohol consumption, serum cholesterol, dyslipidaemia) in the Hai district than in many high-income countries.

Studies in the USA have noted the roles of race and genetics, and of racial differences in socio-economic status, diet and lifestyle, in predicting stroke sub-type incidence..$^{25-26,29-30}$ Nevertheless, Owolabi et al..$^{5}$ suggested that even when comparing cohorts of urban black 
Table IV. CT scan result compared with Siriraj and Allen score, with new cut-offs for Hai patients

\begin{tabular}{|c|c|c|c|c|}
\hline & & \multicolumn{2}{|c|}{ CT scan result } & \multirow[b]{2}{*}{ Total } \\
\hline & & Haemorrhage & Ischaemia & \\
\hline \multirow[t]{7}{*}{ Siriraj score } & Cerebral haemorrhage $(>1)$ & 8 & 15 & 23 \\
\hline & Ischaemic stroke $(\leq 1)$ & 3 & 34 & 37 \\
\hline & Total & 11 & 49 & 60 \\
\hline & $\kappa$ & 0.296 & & \\
\hline & Sensitivity & 0.727 & 0.694 & \\
\hline & Specificity & 0.694 & 0.727 & \\
\hline & Accuracy & 0.700 & & \\
\hline \multirow[t]{7}{*}{ Allen score } & Cerebral haemorrhage $(>27)$ & 7 & 9 & 33 \\
\hline & Ischaemic stroke $(\leq 27)$ & 4 & 40 & 30 \\
\hline & Total & 11 & 49 & 63 \\
\hline & $\kappa$ & 0.385 & & \\
\hline & Sensitivity & 0.636 & 0.816 & \\
\hline & Specificity & 0.816 & 0.636 & \\
\hline & Accuracy & 0.746 & & \\
\hline
\end{tabular}

Table V. CT scan result compared with Siriraj and Allen scores with new cut-offs for Dar-es-Salaam patients

\begin{tabular}{|c|c|c|c|c|}
\hline & & \multicolumn{2}{|c|}{ CT scan result } & \multirow[b]{2}{*}{ Tota } \\
\hline & & Haemorrhage & Ischaemia & \\
\hline \multirow[t]{7}{*}{ Siriraj score } & Cerebral haemorrhage $(\geq 1)$ & 3 & 3 & 6 \\
\hline & Ischaemic stroke $(<1)$ & 0 & 10 & 10 \\
\hline & Total & 3 & 13 & 16 \\
\hline & $\kappa$ & 0.556 & & \\
\hline & Sensitivity & 1.000 & 0.769 & \\
\hline & Specificity & 0.769 & 1.000 & \\
\hline & Accuracy & 0.812 & & \\
\hline \multirow[t]{7}{*}{ Allen score } & Cerebral haemorrhage $(>20)$ & 2 & 2 & 4 \\
\hline & Ischaemic stroke $(\leq 20)$ & 1 & 11 & 12 \\
\hline & Total & 3 & 13 & 16 \\
\hline & $\kappa$ & 0.455 & & \\
\hline & Sensitivity & 0.667 & 0.846 & \\
\hline & Specificity & 0.846 & 0.667 & \\
\hline & Accuracy & 0.812 & & \\
\hline
\end{tabular}

Africans and urban Caucasian Europeans the incidence of stroke due to cerebral haemorrhage, and associated risk factors, is still higher in Africans.

Urban dwellers from Africa have a higher incidence of hypertension than those from rural communities, with a rise in blood pressure seen on migration from the countryside to cities. ${ }^{31-32}$ In Hai $73.3 \%$ and in Dar-es-Salaam $73.8 \%$ of participants were hypertensive (cut-off $\geq 140 / 90 \mathrm{mmHg}$ ), compared with $99 \%$ of hypertensive stroke patients using the same cut-off in Ibadan, Nigeria. ${ }^{5}$ Although not statistically significant, the Hai cohort had lower rates of hypertension than the Dar-es-Salaam cohort. This may in part be due to the relatively good coverage of primary health care services in Hai compared with SSA as a whole, ${ }^{27}$ which in turn may account for the fact that over $60 \%$ of those with hypertension in the Hai DSS had had their blood pressure monitored in the 12 months before interview, compared with less than 30\% in Dar-es-Salaam.

Both the Siriraj and Allen scoring systems are poor at classifying strokes into sub-types. This is not surprising given that, of the clinical findings used to calculate the Siriraj and Allen scores, only level of consciousness 24 hours after admission was significantly associated with CT scan result in the Hai cohort. Clinicians need to rule out cerebral haemorrhage before commencing treatment with anticoagulants, antiplatelets or thrombolytics. In differentiating cerebral haemorrhage from non-cerebral haemorrhage strokes, the Siriraj score was marginally better than the Allen score in both Hai and Dar-es-Salaam. However, low specificity and sensitivity 


\section{Original Articles}

suggest that it would be of little clinical use. Connor et al. ${ }^{6}$ in South Africa came to similar conclusions, although we have found even lower levels of agreement between clinical score and CT scan result. Employing new cut-off scores increases the performance of both scores, although their clinical use is still questionable.

\section{Conclusion}

To the best of our knowledge this is the first prospective study of stroke sub-types in an incident population in SSA. The incidence of stroke due to cerebral haemorrhage is lower than previously reported, and similar to rates seen in high-income countries. Given the lack of CT scanning equipment in SSA there remains a need for a clinically effective screening tool for determining stroke sub-type.

We thank all health care workers, officials, carers and family members who helped in the identification of patients, the inputting of data and the examination and assessment process.

Conflicting interests. There were no conflicts of interest.

Funding. The TSIP study was funded by a grant from the Wellcome Trust, UK.

References

1. Lopez AD, Mathers CD, Ezzati M, Jamison DT, Murray CJL. Global and regional burden of disease and risk factors, 2001: systematic analysis of population health data. Lancet 2006;367:1747-1757.

2. O'Donnell MJ, Xavier D, Liu L, et al. Risk factors for ischaemic and intracerebral haemorrhagic stroke in 22 countries (the INTERSTROKE study): a case-control study. Lancet 2010;376:112-123.

3. Inzitari D, Hachinski V, Taylor W, Barnett H. Racial differences in the anterior circulation in cerebrovascular disease. Arch Neurol 1990;47:1080-1084

4. Hsu RT, Ardron ME, Brooks W, Cherry D, Taub NA, Botha JL. The 1996 Leicestershire Community Stroke \& Ethnicity Study: differences and similarities between South Asian and white strokes. Int Epidemiol 1999;28:853-858.

5. Owolabi MO, Ugoya S, Platz T. Racial disparity in stroke risk factors: the Berlin-Ibadan experience; a retrospective study. Acta Neurol Scand 2009;119:81-87.

6. Connor MD, Modi G, Warlow CP. Accuracy of the Siriraj and Guy's Hospital stroke scores in urban South Africans. Stroke 2007;38:62-68.

7. Ogun SA, Oluwole O, Fatade B, Ogunseyinde AO, Ojini FI, Odusote KA. Comparison of Siriraj Ogun SA, Oluwole O, Fatade B, Ogunseyinde AO, Ojini FI, Odusote KA. Comparison of Siriraj
stroke score and the WHO criteria in the clinical classification of stroke subtypes. Afr I Med Med Sci stroke score and the WHO criteria in the clinical classification of stroke subtypes. Afr J Med Med Sci

8. Zenebe G, Asmera J, Alemayehu M. How accurate is Siriraj stroke score among Ethiopians? A brief communication. Ethiop Med J 2005;43:35-38.

9. Kolapo KO, Ogun SA, Danesi MA, Osalusi BS, Odusote KA. Validation study of the Siriraj stroke score in African Nigerians and evaluation of the discriminant values of its parameters: a preliminary prospective CT scan study. Stroke 2006;37:1997-2000.
10. El Khamlichi A. African neurosurgery: current situation, priorities, and needs. Neurosurgery 2001;48:1344-1347.

11. Allen CMC. Clinical diagnosis of the acute stroke syndrome. Q J Med 1983;52:515-523.

12. Poungvarin N, Viriyavejakal A, Komontri C. Siriraj stroke score and validation study to distinguish supratentorial intracerebral haemorrhage from infarction. BMI 1991;302:1565-1567.

13. Sandercock PAG Allen CMC Corston RN Harrison MJG, Warlow CP. Clinical diagnosis of intracranial a

14. Celani MG, Righetti E, Migliacci R, et al. Comparability and validity of two clinical scores in the early Celani MG, Righetti E, Migliacci R, et al. Comparability and val
differential diagnosis of acute stroke. BMJ 1994;308:1674-1676.

differential diagnosis of acute stroke. BMJ 1994;308:1674-1676.

5. Hawkins GC, Bonita R, Broad JB, Anderson NE. Inadequacy of clinical s
stroke subtypes in population-based studies. Stroke 1995;26:1338-1342.

6. Akpunonu BE, Mutgi AB, Lee L, Khuder S, Federman DJ, Roberts C. Can a clinical score aid in early diagnosis and treatment of various stroke syndromes? Am J Med Sci 1998;315:194-198.

7. Walker $\mathrm{R}$, Whiting $\mathrm{D}$, Unwin $\mathrm{N}$, et al. Stroke incidence in rural and urban Tanzania: a prospective, community-based study. Lancet Neurol 2010;9:786-792.

18. Adult Morbidity and Mortality Project (AMMP). Policy Implications of Adult Morbidity and Mortality: Final Report. Dar-es-Salaam: Tanzanian Ministry of Health, 2004 (updated 3 April 2010). http:// research.ncl.ac.uk/ammp/finrep/ (accessed 3 November 2010).

19. Mahoney FI, Barthel D. Functional evaluation: The Barthel Index. Maryland State Medical Journal 1965;14:56-61.

20. Bonita R, Beaglehole R. Modification of Rankin Scale: Recovery of motor function after stroke. Stroke 1988:19:1497-1500.

21. Sandercock P, Molyneux A, Warlow C. Value of computerised tomography in patients with stroke: the Oxfordshire Community Stroke Project. BMJ 1985;290:193-207.

22. Bamford JM, Sandercock PAG, Warlow CP, Gray M. Why are patients with acute stroke admitted to hospital? The experience of the Oxfordshire Community Stroke Project. BMJ 1986;292:1369-1372.

23. Dennis MS, Bamford JM, Warlow CP. Strokes among black people in Harare, Zimbabwe. BMJ 1986;293:134.

24. Walker RW, McLarty DG, Kitange HM, et al. Stroke mortality in urban and rural Tanzania. Lancet 2000;355:1684-1687.

25. McGruder HF, Malarcher AM, Antoine TL, Greenlund KJ, Croft JB. Racial and ethnic disparities in cardiovascular risk factors among stroke survivors: United States 1999 to 2001. Stroke 2004;35:1557-1561.

26. Sacco RL, Boden-Albala B, Abel G, et al. Race-ethnic disparities in the impact of stroke risk factors: the northern Manhattan stroke study. Stroke 2001;32:1725-1731.

27. Edwards R, Unwin N, Mugusi $\mathrm{F}$, et al. Hypertension prevalence and care in an urban and rural area of Tanzania. J Hypertens 2000;18:145-152.

28. Swai ABM, McLarty DG, Kitange HM, et al. Low prevalence of risk factors for coronary heart disease Swai ABM, McLarty DG, Kitange HM, et al. Low pre
in rural Tanzanians. Int J Epidemiol 1993;22:651-159.

29. Qureshi AI, Giles WH, Croft JB. Racial differences in the incidence of intracerebral hemorrhage: effects 9. Qureshi AI, Giles WH, Croft JB. Racial differences in the inciden
of blood pressure and education. Neurology 1999;52:1617-1621.

30. Bravata DM, Wells CK, Gulanski B, et al. Racial disparities in stroke risk factors: the impact of socioeconomic status. Stroke 2005;36:1507-1511.

1. Poulter NR, Khaw KT, Hopwood BEC, et al. The Kenya Luo migration study: observations on the initiation of a rise in blood pressure. BMJ 1990;300:967-972.

32. Nissinen A, Bothig S, Granroth H, Lopez AD. Hypertension in developing countries. World Health Stat Q 1988;41:141-154.

33. Haynes RB, Sackett DL, Guyatt GH, Tugwell P. Clinical Epidemiology: How to do Clinical Practice Research. 3rd ed. Philadelphia: Lippincott Williams \& Wilkins, 2006.

Accepted 29 November 2010. 